\title{
Dry Socket and Its Management - An Overview
}

Santhosh kumar ${ }^{1 *}$, Suhas Manoharan ${ }^{2}$, Nabeel Nazar ${ }^{3}$

${ }^{1}$ Reader, Department of Oral and Maxillofacial Surgery, Saveetha Dental College and Hospital, Saveetha University.

${ }^{2}$ Department of Oral and Maxillofacial Surgery, Saveetha Dental College and Hospital, Saveetha University.

${ }^{3}$ Reader, Department of Oral and Maxillofacial Surgery, Saveetha Dental College and Hospital, Saveetha University.

\section{Abstract}

\begin{abstract}
Alveolar Osteitis (AO) is an inflammation of the alveolar process of maxilla or mandible. Though self-limiting, the condition sometimes lasts up to 7 days post extraction characterized by dull aching radiating pain which may reach the temple, eye or neck. This article discusses the etiology, pathogenesis, risk factors for dry socket and also elaborates the various methods and techniques in the prevention and management of dry socket. Etiology of alveolar Osteitis has not been well established; with ranging descriptive definitions and diagnostic criteria exist to elucidate alveolar Osteitis. Alveolar Osteitis is a complication that can be avoided by taking necessary preventive measures. It can be prevented by use of antibiotics, irrigation, and maintenance of oral hygiene. Despite lots of research being done, there is no clarity regarding the management of dry socket. Though there is no specific treatment for alveolar osteitis, eugenol dressings and curettage cut back the incidence of it. Studies did lack proper analysis and clear answers regarding the management of dry socket. There is yet no universally accepted preventive measure or management and further detailed studies are necessary to establish concrete conclusions.
\end{abstract}

Keywords: Dry socket; AlveolarOsteitis; Management; Fibrinolysis; Dental Extractions; Alvogyl; Eugenol; Complication.

\section{Introduction}

Alveolar Osteitis (AO) or dry socket is a complication that occurs after extraction of tooth especially third molars. This postsurgical complication also called as dry socket is most commonly seen after 2-3 days after extraction of the tooth. The terminology 'dry socket' was first specified in literature in 1896 [1]. Other commonly used terms include alveolitissicca dolorosa, localised Osteitis, alveolar Osteitis, necrotic socket or septic socket and alveolagia. This complication may cause repeated visits to the clinician and maybe of great inconvenience to both patient and clinician. Such a complication results in severe pain and eventually leading to increased cost of treatment for both patient and operator. Dry socket generally results in pain on the second to fourth day following dental extraction. Post extraction ache normally occurs after the anaesthesia or analgesia has worn off, or has a more delayed onset [2]. Examination normally entails gentle irrigation with warm saline and probing of the socket to establish the diagnosis. On occasion, part of the root of the teeth or a chunk of bone fractures off and is retained in the socket.

Alveolar Osteitis (AO) is simply an inflammation of the alveolar process of maxilla or mandible. Though self-limiting, the condition sometimes lasts up to 7 days post extraction characterized by dull aching radiating pain which may reach the temple, eye or neck. At times the pain can be so severe that it cannot even be relieved by analgesics [3]. Halitosis is a common symptom. The term alveolar Osteitis is taken into consideration synonymous with "dry socket"; however, some believe that dry socket means a focal or localized alveolar Osteitis [4]. An instance of any other kind of Osteitis is focal sclerosing/condensing Osteitis. The phrase dry socket is used due to the fact that the socket has a dry appearance once the blood clot is lost and particles are washed away. Alveolar Osteitisusually does not show any signs such as fever or

*Corresponding Author:

Santhosh kumar,

Reader, Department of Oral and Maxillofacial Surgery, Saveetha Dental College and Hospital, Saveetha Institute of Medical and Technical Sciences (SIMATS) Saveetha University 162, Poonamallee High Road, Velappanchavadi, Chennai 600077 Tamil Nadu, India. Tel: 9994892022

Email Id: santhoshsurgeon@gmail.com

Received: March 01, 2021

Accepted: March 20, 2021

Published: April 02, 2021

Citation: Santhosh kumar, Suhas Manoharan, Nabeel Nazar. Dry Socket and Its Management - An Overview. Int J Dentistry Oral Sci. 2021;08(04):2158-2161. doi: http://dx.doi. org/10.19070/2377-8075-21000426

Copyright: Santhosh kumar 2021 . This is an open-access article distributed under the terms of the Creative Commons Attribution License, which permits unrestricted use, distribution and reproduction in any medium, provided the original author and source are credited. 
lymphadenitis; only erythema and minimal oedema is present in the soft tissues around the socket. Signs may include an empty socket, which is partially or totally devoid of blood clot. Bone may be visible or the socket may contain food debris which on removal exposes the bone [5]. The exposed bone is sensitive and painful on touch. Inflamed soft tissues surrounding the socket may overlie the socket and hide the dry socket from examination.

\section{Etiology Of Dry Socket}

Most authors concur that surgical injury assume a huge part in formation of AO. Surgical extractions, in contrast with nonsurgical extractions, result in higher incidence rate of AO [6]. Lilly et al. [7] found that surgical extractions involving reflection of flap and removal of bone will probably cause AO. Numerous investigations assert that administrator's experience is a hazard factor for development of AO. Larsen [8] presumed that specialist's naiveté could be identified with a greater injury amid the extraction, particularly surgical extraction of mandibular third molars. Alexander [1] and Oginni et al. [9] announced a higher occurrence of AO following extractions performed by the less experienced administrators. Subsequently the aptitude and experience of the administrator ought to be contemplated. It is also believed that alveolar Osteitis is a common occurrence post extraction of mandibular third molars. It isexplained that reduced vascularity, decreased ability to produce granulation tissue and increased bone density maybe the causative factors [10]. However, there is no proof regarding decreased vascularity and alveolar Osteitis. The reason for such site-specific occurrence maybe due to alarge percentage of mandibular third molar extractions [11].

Physical removal or dislodgement of the clot is also a popularly discussed theory which maybe probably due to negative pressure created during situation like sucking through a straw. However, there is no solid evidence regarding this issue. The cause of dry socket is not absolutely understood [12]. Typically, following extraction of a tooth, blood is extravagated into the socket, and a blood clot is formed. This blood clot is replaced with granulation tissue which consists of fibroblasts and endothelial cells derived from remnants of the periodontal membrane, surrounding alveolar bone and gingival mucosa. In time this in turn is changed to coarse, fibrillar bone and ultimately to mature, woven bone. The clot may fail to form due to poor blood supply. The poor blood supply maybe due tofactors such as smoking, anatomical site, bone density and conditions which cause sclerotic bone to form. The clot can also be misplaced due to excessive mouth rinsing, or collapse in advance due to fibrinolysis [13] Fibrinolysis is the degeneration of the clot and can be because of the conversion of plasminogen to plasmin and formation of kinins. Elements which promote fibrinolysis include local trauma, oestrogens, and pyroxenes from microorganism [14].

Microorganism may additionally colonize the socket, and result in dissolution of the clot. Bacterial breakdown and fibrinolysis are the important contributing factors to the lack of the clot. Bone tissue is uncovered to the oral environment, and a localized inflammatory reaction takes vicinity with in the adjoining marrow areas. This localizes the irritation to the walls of the socket, which becomes necrotic. The necrotic bone in the socket is slowly separated by osteoclasts and fragmentary sequestra may also form. The bones of the jaws seem to have a few evolutionary resistances to this procedure [15].

\section{Pathogenesis Of Dry Socket}

Recovery from Alveolar Osteitis is slow and gradual because tissue should develop from the surrounding gingival mucosa, which takes longer than the regular formation of a blood clot.

Rozantis et al [16] studied the relationship between streptococcus mutans and alveolar Osteitis. Delayed healing was seen in extraction sites after microorganisms were inoculated in to the extraction sites. Bacteria and microorganisms are known to cause alveolar Osteitis. Patients with poor oral hygiene, periodontitis, pericoronitis and other advanced periodontal conditions are known to show increased incidence of alveolar Osteitis [17]. Violent curettage or irrigation of the socket may also cause dislodgement of the clot formed and cause a dry socket. There also theories suggestive of a female predilection. Alveolar Osteitis is associated with the usage of oral contraceptives. Oral contraceptives became popular in the early 1960s and a positive correlation was seen between occurrence of alveolar Osteitis and usage of oral contraceptives [18]. This correlation is due to oestrogen levels as the oestrogen hormone plays a major role in fibrinolysis. It is believed that oestrogen activates the fibrinolytic process leading to increases in certain factors such as II. VII, VIII and X and plasminogen causing lysis of the blood clot.

Moreover, in a series of 4000 extractions, it was found that there was clear female predilection irrespective of the usage of oral contraceptives [18]. A fibrin clot is made of thromb in and fibrinogen in a post extraction socket and over this, the epithelium migrates. New blood vessels grow into the clot during granulation tissue formation and this clot degrades through the activity of fibroblast and fibrinolysis through the plasmin before the start of osteoproliferation. Birn [19] discovered that the plasmin like activity in dry sockets was not present at normal extraction sites. Kinases are liberated during inflammation through direct or indirect activation of plasminogen in the blood. These kinases cause lysis and destruction of the blood clot. Tissue or plasma activators activate and convert the plasminogen to fibrin, resulting in the dissolution of the clot by disintegration of fibrin. This plasminogen pathway activation, can be direct (physiologic) or indirect (non-physiologic). Direct activators are released to the alveolar bone cells after trauma. Indirect activators are released by bacteria. Direct extrinsic activators are tissue plasminogen activators and endothelial plasminogen activators. Direct intrinsic activators include the components of plasma such as factor XII, urokinase [20].

\section{Risk Factors For Dry Socket}

Patients with systemic illness such as diabetes or otherimmunocompromised conditions also have higher incidences of alveolar Osteitis due to impaired healing of the wound. It is also seen that incidence of dry socket increases with age. Hence it is advised to perform any mandibular third molar extraction before the age of $24 y r s$ especially among females to prevent occurrence of alveolar Osteitis. Smoking is alsoa major risk factor for alveolar Osteitis. Remnants of tooth root or bone fragments can also result in disturbed or poor wound healing which may cause alveolar Osteitis. Radiotherapy might decrease the blood supply to alveolar bone which may lead to occurrence of a dry socket [21].

It was inferred that utilization of local anaesthesia with vaso- 
constrictors will increase the incidence of AO. It was also found that $\mathrm{AO}$ frequency will increase with infiltration anaesthesia as a result of the ischemia that ends up in poor or reduced blood supply [22]. However, the studies that followed indicated that the ischemia remains for only about two hours and is replaced by reactive hyperaemia, which makes it inapplicable for disintegration of the blood clot [23]. One study conveyed that there is no significant difference in $\mathrm{AO}$ prevalence following extraction of teeth requiring infiltration anaesthesia versus regional block anaesthesia with vasoconstrictor [24]. It is presently accepted that local ischemia owing to vasoconstrictve effect of local anaesthesia has no role in the development of AO. Limited proof suggests higheroccurrence of $\mathrm{AO}$ during single extractions on contrast to multiple extractions. According to one study, AO prevalence was $7.3 \%$ following single extractions and $3.4 \%$ following multiple extractions [25]. This difference could be as a result of less pain tolerance in patients who come for single tooth extractions. Also, it could be that most patients with multiple extractions have periodontally compromised teeth or unhealthy dentition.

\section{Prevention Of Dry Socket}

As AO is a commonly occurring complication after tooth extractions, a lot studies have been done and many theories and techniques have been put forward to help in preventing alveolar osteitis. But still no single method or technique has been universally accepted in the prevention of AO. Systemic and topical antibiotics have been proposed to prevent $\mathrm{AO}$, however there are arguments claiming that regular use of topical antibiotics have led to resistance among certain strains of bacteria. Topical tetracycline claimed to be effective but it showed foreign body reaction on topical application. Commonly used systemic antibiotics to treat $\mathrm{AO}$ are clindamycin, erythromycin and metronidazole [26].

An author suggested that placing any medicament into the alveolus will show certain degree of improvement in case of alveolar Osteitis [27]. Analgesics such as acetaminophen with oxycodone, codeine or hydroxycodone maybe used. Many studies also suggest the usage of $0.12 \%$ chlorhexidine mouthwash after extraction of mandibular third molars result in decreased occurrence of dry socket [28-32]. Also, usages of antifibrinolytic agents such as para-hydroxybenzoic acid or PHBA and tranexamic acid have shown to reduce the incidence of alveolar Osteitis. PHBA is known to have anti-microbial effects but is known to impair bone healing from animal studies. Meanwhile, tranexamic acid is not widely accepted and is not proved to reduce the incidence of alveolar Osteitis. The usage of an antiseptic agent 9-aminoacridine was speculated to reduce the incidence of AO however there is no evidence to support this claim. Eugenol was promoted to be used along with dressings but the irritant effect leading to delayed wound healing has been well described in literature and hence is not commonly preferred to prevent the incidence of alveolar Osteitis [33-35].

\section{Management Of Dry Socket}

Management of alveolar Osteitis is not as speculative as prevention. Alveolar Osteitis is a self-healing condition and there is no established treatment for alveolar Osteitis. Analgesics and antibiotics are recommended to relieve pain. Medicated dressings are also mentioned in literature however, intra alveolar dressings are known to delay the wound healing process. Alvogyl containing butamben ananaesthetic, eugenol an analgesic and iodoforman antimicrobial agent are used to pack the sockets. However certain studies claim packing with alvogyl caused marked inflammation and retarded healing $[36,37]$.

\section{Summary}

Alveolar Osteitis is a complication that can be avoided by taking necessary preventive measures. Despite lots of research being done, there is no clarity regarding the management of dry socket. Very little progress has been created in addressing this usually encountered and unsightly surgical condition in patients. Literature related to alveolar Osteitis is not consistent and is conflicting. Studies are poorly done, have variable styles and applied mathematics, biases, lack analysis, or encompass individual opinions. Etiology of alveolar Osteitis has not been well established; with ranging descriptive definitions and diagnostic criteria exist to elucidate alveolar Osteitis. This lack of over simplified answerconsistent with one author, is the result of the initiation of fibrinolytic method which seems to be associated with associate interfacing of multiple freelance factors. Analysis done to prevent this complication have yielded no single universally acceptable technique or success. However, a large number of intra-alveolar medicaments are instructed in the literature and are offered on the market. Even if complications or severe reactions from preparations placed with in the socket are rare, most have rumoured some negative reactions. If adverse reactions do occur, this body of literature does not offer enough support for the treating practician. The formula to management of this complication ought to begin with patient education and patients with classifiable risk factors ought to learn intimately concerning this anticipated complication. Any investigation and well-designed studies are necessary to draw firm conclusions and to clarify this complication.

\section{Conclusion}

The prevalence of dry socket is inevitable. It can be prevented by use of antibiotics, irrigation, and maintenance of oral hygiene. Though there is no specific treatment for alveolar osteitis, eugenol dressings and curettage cut back the incidence of it. Studies did lack proper analysis and clear answers regarding the management of dry socket. There is yet no universally accepted preventive measure or management. Further studies and investigations need to be done to establish concrete conclusions.

\section{References}

[1]. Alexander RE. Dental extraction wound management: a case against medicating postextraction sockets. J Oral Maxillofac Surg. 2000 May 1;58(5):538-51.PubmedPMID: 10800910.

[2]. Birn H. Etiology and pathogenesis of fibrinolyticalveolitis ("dry socket"). International journal of oral surgery. 1973 Jan 1;2(5):211-63.

[3]. Brekke JH, Bresner M, Reitman MJ. Effect of surgical trauma and polylactate cubes and granules on the incidence of alveolar osteitis in mandibular third molar extraction wounds. J Can Dent Assoc. 1986 Apr;52(4):315-9. PubmedPMID: 3518884 .

[4]. Colby RC. The general practitioner's perspective of the etiology, prevention, and treatment of dry socket. Gen Dent. 1997 Sep-Oct;45(5):461-7. PubmedPMID: 9515413.

[5]. Field EA, Speechley JA, Rotter E, Scott J. Dry socket incidence compared after a 12 year interval. Br J Oral Maxillofac Surg. 1985 Dec;23(6):419-27. Pubmed PMID: 2933062.

[6]. Torres-Lagares D, Serrera-Figallo MA, Romero-Ruíz MM, Infante-Cossío P, García-Calderón M, Gutiérrez-Pérez JL. Update on dry socket: a review 
of the literature. Med Oral Patol Oral Cir Bucal. 2005 Jan-Feb;10(1):81-5; 77-81. English, Spanish. Pubmed PMID: 15627911.

[7]. Lilly HA, Lowbury EJ, Wilkins MD, Zaggy A. Delayed antimicrobial effects of skin disinfection by alcohol. J Hyg (Lond). 1979 Jun;82(3):497-500. Pubmed PMID: 448066.

[8]. Larsen PE. Alveolar osteitis after surgical removal of impacted mandibular third molars: Identification of the patient at risk. Oral Surg Oral Med Oral Pathol. 1992 Apr;73(4):393-7. Pubmed PMID: 1574298.

[9]. Oginni FO, Fatusi OA, Alagbe AO. A clinical evaluation of dry socket in a Nigerian teaching hospital. J Oral Maxillofac Surg. 2003 Aug;61(8):871-6. Pubmed PMID: 12905436

[10]. Blum IR. Contemporary views on dry socket (alveolar osteitis): a clinical appraisal of standardization, aetiopathogenesis and management: a critical review. Int J Oral Maxillofac Surg. 2002 Jun;31(3):309-17. Pubmed PMID: 12190139.

[11]. Amaratunga ND, Senaratne CM. A clinical study of dry socket in Sri Lanka. Br J Oral Maxillofac Surg. 1988 Oct;26(5):410-8. Pubmed PMID: 3056513.

[12]. Jaafar N, Nor GM. The prevalence of post-extraction complications in an outpatient dental clinic in Kuala Lumpur Malaysia--a retrospective survey. Singapore Dent J. 2000 Feb;23(1):24-8. Pubmed PMID: 11602946.

[13]. Rud J. Removal of impacted lower third molars with acute pericoronitis and necrotising gingivitis. Br J Oral Surg. 1970 Mar;7(3):153-60. Pubmed PMID: 5272558.

[14]. Peñarrocha M, Sanchis JM, Sáez U, Gay C, Bagán JV. Oral hygiene and postoperative pain after mandibular third molar surgery. Oral Surg Oral Med Oral Pathol Oral RadiolEndod. 2001 Sep;92(3):260-4. Pubmed PMID: 11552141.

[15]. Ygge J, Brody S, Korsan-Bengtsen K, Nilsson L. Changes in blood coagulation and fibrinolysis in women receiving oral contraceptives. Comparison between treated and untreated women in a longitudinal study. Am J Obstet Gynecol. 1969 May 1;104(1):87-98. Pubmed PMID: 4180662.

[16]. J. Rozanis, I. D. Schofield, B. A. Warren, "Is dry socket preventable?" Dental Journal.1977; 43(5):233-236.

[17]. MacGregor AJ. Aetiology of dry socket: a clinical investigation. Br J Oral Surg. 1968 Jul;6(1):49-58. Pubmed PMID: 5244107.

[18]. Blondeau F, Daniel NG. Extraction of impacted mandibular third molars: postoperative complications and their risk factors. J Can Dent Assoc. 2007 May;73(4):325. Pubmed PMID: 17484797.

[19]. Birn H. Bacteria and fibrinolytic activity in "dry socket". ActaOdontologicaScandinavica. 1970 Jan 1;28(6):773-83.

[20]. Moore JW, Brekke JH. Foreign body giant cell reaction related to placement of tetracycline-treated polylactic acid: Report of 18 cases. Journal of Oral and Maxillofacial Surgery. 1990 Aug 1;48(8):808-12.

[21]. Bystedt H, Nord CE, Nordenram A. Effect of azidocillin, erythromycin, clindamycin and doxycycline on postoperative complications after surgical removal of impacted mandibular third molars. Int J Oral Surg. 1980 Jun;9(3):157-65. Pubmed PMID: 6777314.
[22]. Larsen PE. The effect of a chlorhexidine rinse on the incidence of alveolar osteitis following the surgical removal of impacted mandibular third molars. J Oral Maxillofac Surg. 1991 Sep;49(9):932-7. PubmedPMID: 1886022.

[23]. Hermesch CB, Hilton TJ, Biesbrock AR, Baker RA, Cain-Hamlin J, McClanahan SF, Gerlach RW. Perioperative use of $0.12 \%$ chlorhexidinegluconate for the prevention of alveolar osteitis: efficacy and risk factor analysis. Oral Surg Oral Med Oral Pathol Oral RadiolEndod. 1998 Apr;85(4):381-7. Pubmed PMID: 9574945.

[24]. Tjernberg A. Influence of oral hygiene measures on the development of alveolitissicca dolorosa after surgical removal of mandibular third molars. Int J Oral Surg. 1979 Dec;8(6):430-4. Pubmed PMID: 120340.

[25]. Birn H. Antifibrinolytic effect of Apernyl ${ }^{\circledR}$ in "dry socket". International journal of oral surgery. 1972 Jan 1;1(4):190-4.

[26]. Malay KK, Duraisamy R, Brundha MP, Kumar MP. Awareness regarding anemia among 1 st year dental undergraduate students. Drug Invention Today. 2018 Aug 1;10(8).

[27]. Kumar MS. Knowledge, attitude and practices towards oral health among law students in Chennai. Journal of Pharmaceutical Sciences and Research. 2016 Jul 1;8(7):650.

[28]. Kumar MP. Dental management of patients on antiplatelet therapy: Literature update. Asian J Pharm Clin Res. 2016;9(3):26-31

[29]. Kumar S. Newer delivery systems for local anesthesia in dentistry. J Pharm Sci Res. 2015;7(5):252-5.

[30]. Ahamed A, Kumar MS. Knowledge, attitude and perceived confidence in handling medical emergencies among dental students. J IntSocPrev Community Dent. 2017 Nov-Dec;7(6):364-369. PubmedPMID: 29387622.

[31]. Kumar S. Knowledge, attitude and practices of dental students toward dental management of patients on antiplatelet therapy. Asian J Pharm Clin Res. 2016;9(30):270-6.

[32]. Gayathri MM. Knowledge, Awareness and Attitude among dental students about hepatitis B infection. Journal of Pharmaceutical Sciences and Research. 2016 Mar 1;8(3):168.

[33]. Kumar SM. Knowledge, Attitude and practices regarding needlestick injuries among dental students. Asian Journal of Pharmaceutical and Clinical Research. 2016;9(4):312-5.

[34]. Ritzau M. The prophylactic use of tranexamic acid (Cyklokapron ${ }^{\circledR}$ ) on alveolitissicca dolorosa. International Journal of Oral Surgery. 1973 Jan $1 ; 2(5): 196-9$.

[35]. Johnson WS, Blanton EE. An evaluation of 9-aminoacridine/gelfoam to reduce dry socket formation. Oral Surgery, Oral Medicine, Oral Pathology. 1988 Aug 1;66(2):167-70.

[36]. Sivakumar N, Sundari KK, Chandrasekar S, Kumar MP. A review on smile arc-An orthodontist's perspective. Drug Invention Today. 2018 Sep 2;10.

[37]. Bloomer CR. Alveolar osteitis prevention by immediate placement of medicated packing. Oral Surg Oral Med Oral Pathol Oral RadiolEndod. 2000 Sep 1;90(3):282-4.PubmedPMID: 10982947. 